OPEN ACCESS

Edited by:

Zaleha Abdullah Mahdy,

National University of

Malaysia, Malaysia

Reviewed by:

Jagidesa Moodley,

University of KwaZulu-Natal,

South Africa

Shuhaila Ahmad,

National University of

Malaysia, Malaysia

${ }^{*}$ Correspondence:

Juan Du

duj@sj-hospital.org

Specialty section: This article was submitted to

Obstetrics and Gynecology,

a section of the journal

Frontiers in Medicine

Received: 25 April 2021

Accepted: 12 July 2021

Published: 02 August 2021

Citation:

Cai B, Yuan X, Li X, XU J and Du J (2021) Urinary Congophilia Confirmed With the CapCord Test is Associated With Pregnancy Outcomes in Women With Early-Onset Pre-eclampsia.

Front. Med. 8:700157.

doi: 10.3389/fmed.2021.700157

\section{Urinary Congophilia Confirmed With the CapCord Test Is Associated With Pregnancy Outcomes in Women With Early-Onset Pre-eclampsia}

\author{
Benshuo Cai ${ }^{1}$, Xiaoying Yuan ${ }^{2}$, Xingmin $\mathrm{Li}^{2}$, Jun $\mathrm{Xu}^{2}$ and Juan $\mathrm{Du}{ }^{1 *}$ \\ ${ }^{1}$ Department of Obstetrics and Gynecology, Shengjing Hospital of China Medical University, Shenyang, China, ${ }^{2}$ Shuwen \\ Biotech Company Ltd., Deqing, China
}

Background: The association between misfolded proteins presented in the urine of pregnant women and pregnancy outcomes associated with early-onset pre-eclampsia (PE) remains unclear. This study aimed to investigate this association to examine the predictive value of urinary congophilia in the prognostication of pregnancy outcomes in this patient group in the Chinese population.

Materials and Methods: This study included 1,397 patients, of which 46, 147, and 8 patients had gestational hypertension, PE, and chronic hypertension, respectively, and 1,196 were healthy controls undergoing the CapCord test for urinary congophilia. Patients with PE were divided into early- and late-onset groups. Patients with early-onset PE were further divided into iatrogenic prematurity and full-term delivery groups, the rates of urinary congophilia were compared between the groups; additionally, this patient group was divided into positive and negative urinary congophilia groups, clinical characteristics and pregnancy outcomes were compared between the groups. Univariate and multivariate logistic regression analyses were performed.

Results: A total of 113 (76.9\%) of 147 patients in the PE group had urinary congophilia; this rate was higher than that observed in the other three groups $\left(\chi^{2}=780.892, p<\right.$ $0.001)$. Gestational age in the early-onset PE group at both onset and delivery was lower than that in the late-onset PE group $(p<0.001)$. The rates of iatrogenic prematurity and hemolysis, elevated liver enzymes, and low platelet count syndrome were both higher in the early-onset PE group than in the late-onset PE group $(p<0.001, p<0.05)$. In addition, the rate of urinary congophilia in the early-onset PE group was higher than that in the late-onset PE group $\left(\chi^{2}=13.297, p<0.001\right)$. Urinary congophilia was an independent risk factor for iatrogenic prematurity among patients with early-onset PE in both univariate [odds ratio (OR) 17.143, 95\% confidence interval (Cl): 4.719-62.271; $p$ $<0.001$ ] and multivariate (OR 18.174; 95\% Cl: 4.460-74.063; $p<0.001$ ) analyses. Patients with early-onset PE and urinary congophilia were more likely than their counterparts without urinary congophilia to deliver at a lower gestational age, present with iatrogenic prematurity, and have a shorter latency period between onset and delivery. 


\section{Conclusion: Urinary congophilia confirmed with the CapCord test may help predict pregnancy outcomes in patients with early-onset PE.}

Keywords: congophilia, misfolded protein, early-onset pre-eclampsia, late-onset pre-eclampsia, pregnancy outcome

\section{INTRODUCTION}

Pre-eclampsia (PE) is the leading contributor to maternal and fetal mortality worldwide (1). It is defined as new-onset hypertension and proteinuria after 20 weeks of gestation (2), accounting for $17-24 \%$ of maternal deaths in low-income settings (3). Untreated PE may lead to eclampsia, renal damage, cerebrovascular accidents, microangiopathic hemolytic anemia, liver failure, and pulmonary edema, all of which increase the risk of maternal death $(4,5)$. Delivery is the only effective treatment for PE; however, preventing stillbirth and iatrogenic prematurity remains a challenge. Depending on the gestational age at onset, PE is classified as early- (or placental) or lateonset (or maternal) $(6,7)$; these subtypes appear to have different etiologies. Specifically, early-onset PE is associated with abnormal placentation; by contrast, late-onset PE is associated with an interaction between a presumably normal placenta and maternal factors such as endothelial dysfunction and microvascular damage $(8,9)$. The pathogenesis of $\mathrm{PE}$ is yet to be elucidated; however, some evidence suggests that uteroplacental hypoperfusion may lead to PE $(10,11)$. Meanwhile, impaired spiral artery remodeling in the uterus, which may lead to the release of antiangiogenic factors from the ischemic placenta into the maternal circulation, is a two-stage model considered central to research in the pathogenesis of PE (12).

In human cells, linear amino acid multimers can be converted into functional proteins with three-dimensional structures able to perform their function. Some diseases are associated with protein folding disturbance, which results in the formation of misfolded proteins, such as in Alzheimer's and Parkinson's diseases, and prion diseases (13-18). Recent studies have shown that misfolded proteins may accumulate in the urine, serum, and placenta of patients with PE (19-24). Urinary misfolded proteins can be detected by a point-of-care urinary Congo red test (25). Congo red is a kind of synthetic diazo dye with specific affinity for misfolded proteins (26-28). The affinity of misfolded proteins to Congo red is known as congophilia (29, 30). Buhimschi et al. proposed that urine samples of women with PE exhibited congophilia; additionally, the rate of urinary congophilia was higher among women with severe PE with indications for delivery than among their counterparts that were either healthy or diagnosed with chronic or gestational hypertension (21). However, the origin of misfolded proteins in the urine of women with $\mathrm{PE}$ remains unclear. Placental hypoxia and ischemia resulting from impaired placentation in PE may lead to endoplasmic reticulum stress (ERS) in the placenta (31-33). ERS may lead to chronic activation of unfolded protein response (UPR) pathways (34-36), which aim to restore endoplasmic reticulum homeostasis by removing the misfolded proteins. The activation of placental UPR occurs in early- but not in late-onset PE or normotensive controls (33). Based on this evidence, we hypothesized that the placenta may be the main source of the misfolded proteins in the urine of patients with early-onset $\mathrm{PE}$ and the presence of misfolded proteins in the urine may be linked to the pathogenesis of early-onset PE but not late-onset PE. In this study, we, for the first time, compared the urinary congophilia of patients with different types of $\mathrm{PE}$ and normotensive controls in the Chinese population to investigate the association between the presence of misfolded proteins in the urine and early-onset PE, as well as the possible origin of the misfolded proteins in the urine in the Chinese population. Furthermore, we examined the association of urinary congophilia with the pregnancy outcomes in Chinese patients with earlyonset PE to assess the predictive value of urinary congophilia in the prognostication of pregnancy outcomes in this patient group.

\section{MATERIALS AND METHODS}

\section{Study Design}

The protocol of this study was approved by the Institutional Review Board of Shengjing Hospital of China Medical University, Shenyang, Liaoning Province, China (Approval number: 2018PS195K). The need for obtaining informed consent was waived owing to the use of residual urine samples and the minimal risks involved. The study was conducted according to the principles expressed in the Helsinki Declaration.

Pregnant women aged $\geq 18$ years and at the gestational age of $\geq 20$ weeks, admitted to our hospital between May 2017 and August 2018 were eligible for this study. Included patients were divided into gestational hypertensive, PE, chronic hypertensive, and normotensive groups. The PE group was further subdivided into early- and late-onset groups. The patients' clinical characteristics and rates of urinary congophilia were compared among the groups. Pregnancy outcomes of the patients with early-onset PE were categorized as iatrogenic prematurity and full-term delivery. Patients with early-onset $\mathrm{PE}$ were further subdivided into positive and negative urinary congophilia groups.

\section{Diagnostic Criteria}

Hypertensive disorders of pregnancy were determined according to the 2018 International Society for the Study of Hypertension in Pregnancy Classification, Diagnosis, and Management Recommendations for International Practice (2).

Women were excluded from the present study if they were diagnosed with any of the followings: diabetes mellitus, respiratory disease, blood system disease, liver disease, renal disease, heart disease, fetal genetic and congenital malformation, abortion or fetal death, twin or multiple pregnancy, history 
of assisted reproductive technology use, infections or proinflammatory states, autoimmune disease, or cancer. Women with incomplete clinical information were also excluded. Earlyand late-onset $\mathrm{PE}$ were defined by the gestational age at onset of disease, $<34$ and $\geq 34$ weeks, respectively (6).

\section{Urine Sample and Clinical Data Collection}

Midstream urine samples were collected from all patients for the assessment of congophilia. In patients with hypertensive disorders of pregnancy, urine samples were collected at the time of disease onset. All patients with hypertensive disorders of pregnancy were followed-up until post-delivery. Data on maternal age, gestational age at PE onset and delivery, pregnancy outcomes, and the presence of the hemolysis, elevated liver enzymes, and low platelet count syndrome (HELLP syndrome) were collected. Investigators were blinded to any personal data during congophilia measurement.

\section{Detection of Misfolded Proteins in Urine}

A point-of-care device employing the capillary tube-based slow release method (the CapCord test, available from Shuwen Biotech. Zhejiang, China) was used to detect misfolded proteins in urine samples (25). Each scorer classified the pattern of the dye into six categories relative to the reference pattern, based on the evenness of the spread and tendency of the dye to concentrate in a limited central area (Figure 1). All scorers were trained to ensure the consistency of approach.

\section{Statistical Methods}

Clinical characteristics and pregnancy outcomes were compared among the groups, using the analysis of variance or MannWhitney $U$-test. The difference in counts among the groups was assessed with the chi-squared test or Fisher's exact probability test. Univariate and multivariate logistic regression analyses were performed. Survival curves were compared using the KaplanMeier method and the log-rank test. $P$-values $<0.05$ were indicative of significant findings. All statistical analyses were performed using the Statistical Product and Service Solutions (SPSS) software ver. 23.0 (IBM Corp., Armonk, NY, USA).

\section{RESULTS}

This study included 1,397 patients. The CapCord test was performed for all patients. Table 1 presents the incidence of urinary congophilia in four groups. The differences of the rates of positive urinary congophilia among different groups were significant.

Table 2 presents comparisons of the clinical characteristics and rates of urinary congophilia between early- and late-onset PE groups. The gestational age of the early-onset PE group at both $\mathrm{PE}$ onset and delivery was significantly lower than that of the lateonset PE group. The rates of iatrogenic prematurity and HELLP syndrome were both significantly higher in the early- than in the late-onset PE group. In addition, the rate of urinary congophilia in the early-onset PE group was significantly different from that in the late-onset $\mathrm{PE}$ group.

Urinary congophilia was an independent risk factor for iatrogenic prematurity in both univariate [odds ratio (OR)

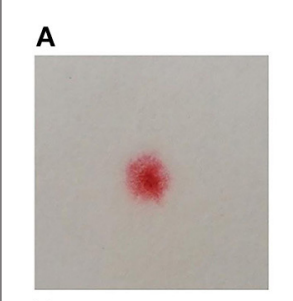

D
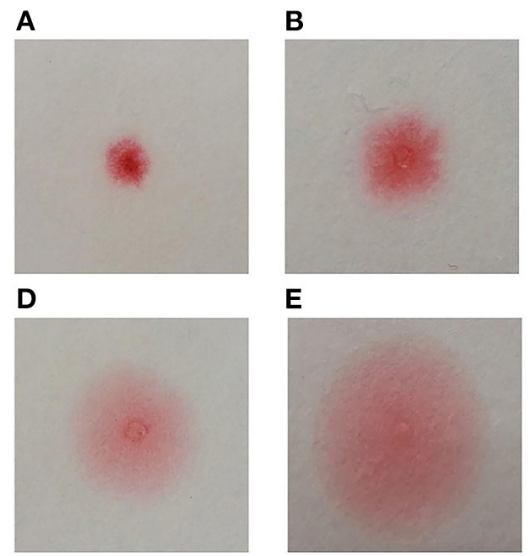

E

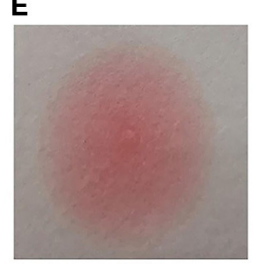

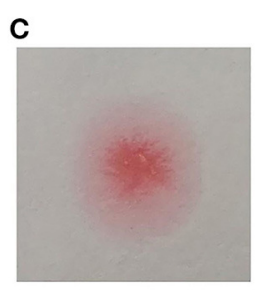

$\mathbf{F}$

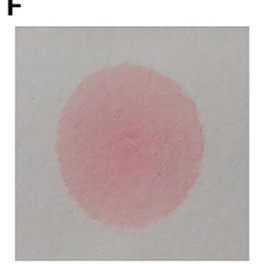

FIGURE 1 | Congo red bound to misfolded proteins in an aqueous solution migrates differentially on cellulose membrane, forming different dyeing patterns. The differences are especially apparent when the solution is slowly released into small area on the cellulose membrane through a fine-tipped capillary tube. The more Congo red is bound to misfolded proteins, the dye spreads more evenly on the membrane. The device we used included a plastic pipette to drop urine to a well-containing Congo red $(0.1 \mathrm{mg} / \mathrm{ml})$, and a capillary applicator to transfer the mixture to cellulose membrane compartment and slowly released. The test produces a result within $3 \mathrm{~min}$. Classification of Congo red staining patterns (A) Small non-diffused red dot; (B) Mildly diffused dot, scarlet pseudopodium; (C) Diffused dot, scarlet pseudopodium, pink penumbra; (D) Small dot, irregular partly diffused pale red penumbra; (E) Red and scarlet dot, partly diffused pale red penumbra; (F) Large uniform pale diffused dot. The patterns (D-F) were classified as "positive" and patterns (A-C) as "negative."

17.143; 95\% confidence interval (CI) 4.719-62.271; $p=0.000]$ (Table 3) and multivariate (OR 18.174; 95\% CI 4.460-74.063; $p$ $=0.000)$ analyses.

A significant difference was found in the gestational age at delivery between patients with and without urinary congophilia in the early-onset PE group. The positive urinary congophilia group presented with a shorter latency period between onset and delivery than did the negative urinary congophilia group; finally, a significant difference was observed in the rate of iatrogenic prematurity between the groups with and without urinary congophilia within the early-onset PE group (Table 4).

In total, 86 patients with iatrogenic prematurity comprised the early-onset PE group. The Kaplan-Meier survival curves showed higher rates of iatrogenic prematurity among patients with urinary congophilia than among their counterparts without this condition ( $\chi^{2}=15.976, p<0.001$ ) (Figure 2). These findings suggest that pregnancy outcomes are poorer in early-onset PE patients with urinary congophilia than in their counterparts without this condition.

\section{DISCUSSION}

Previous studies on the presence of misfolded proteins in PE patients mostly involved Western populations (19-21, 37-39). The present study confirms that urinary congophilia occurs in Chinese women with PE. The 
TABLE 1 | Incidence of positive urinary congophilia in four groups.

\begin{tabular}{lccccc}
\hline Variables & $\begin{array}{c}\text { Gestational } \\
\text { hypertensive } \\
(\boldsymbol{n}=\mathbf{4 6})\end{array}$ & $\begin{array}{c}\text { Pre-eclampsia } \\
(\boldsymbol{n}=\mathbf{1 4 7 )}\end{array}$ & $\begin{array}{c}\text { Chronic } \\
\text { hypertensive } \\
(\boldsymbol{n}=\mathbf{8})\end{array}$ & $\begin{array}{c}\text { Normotensive } \\
(\boldsymbol{n}=\mathbf{1 , 1 9 6 )}\end{array}$ & $\chi^{\mathbf{2}}$ \\
\hline Rate of positive urinary congophilia & $1(2.2 \%)$ & $113(76.9 \%)^{*}$ & $0(0 \%)$ & $31(2.6 \%)$ & 780.892
\end{tabular}

Values are $n$ and $n / N(\%){ }^{*} p<0.001$ vs. gestational hypertensive, chronic hypertensive, and normotensive (chi-squared test or Fisher exact probability test).

TABLE 2 | Clinical characteristics and incidence of positive urinary congophilia in early- and late-onset pre-eclampsia groups.

\begin{tabular}{|c|c|c|c|c|c|}
\hline Variables & Early-onset $(n=102)$ & Late-onset $(n=45)$ & $z$ & $\chi^{2}$ & $P$-value \\
\hline Gestational age at onset & $28.8(26,31.3)$ & $37(35.3,38.2)$ & -9.653 & / & $<0.001$ \\
\hline Gestational age at delivery & $32.6(30.1,35.4)$ & $38.1(36.8,38.6)$ & -7.584 & / & $<0.001$ \\
\hline latrogenic prematurity & $86(84.3 \%)$ & $11(24.4 \%)$ & / & 49.865 & $<0.001$ \\
\hline HELLP syndrome & $18(17.6 \%)$ & $1(2.2 \%)$ & / & 6.601 & $<0.05$ \\
\hline CapCord test-positive & $87(85.3 \%)$ & $26(57.8 \%)$ & & 13.297 & $<0.001$ \\
\hline
\end{tabular}

Values are median (P25, P75), n or n/N (\%). HELLP syndrome, hemolysis, elevated liver enzymes, and low platelet count syndrome.

TABLE 3 | Clinical characteristics of patients with early-onset PE and iatrogenic prematurity or full-term delivery.

\begin{tabular}{|c|c|c|c|c|}
\hline \multirow[t]{2}{*}{ Variables } & \multirow[t]{2}{*}{ latrogenic prematurity $(n=86)$} & \multirow[t]{2}{*}{ Full-term $(n=16)$} & \multicolumn{2}{|c|}{ Univariate analysis } \\
\hline & & & OR (95\%Cl) & $P$-value \\
\hline Age (years) & $30.8 \pm 5.3$ & $31.1 \pm 4.5$ & $0.989(0.891,1.098)$ & 0.842 \\
\hline Gestational age at onset & $28.1 \pm 3.9$ & $26.8 \pm 5.9$ & $1.069(0.948,1.205)$ & 0.279 \\
\hline HELLP & $17(19.8 \%)$ & $1(6.3 \%)$ & $3.696(0.456,29.958)$ & 0.221 \\
\hline Rate of positive urinary congophilia & 80/86 (93.0\%) & 7/16 (43.8\%) & $17.143(4.719,62.271)$ & $<0.001$ \\
\hline
\end{tabular}

Values are mean \pm standard deviation, $n$ or $n / N(\%)$.

TABLE 4 | Clinical characteristics and pregnancy outcomes among patients with positive and negative urinary congophilia and early-onset pre-eclampsia.

\begin{tabular}{|c|c|c|c|c|c|c|}
\hline Variables & $\begin{array}{l}\text { Positive urinary } \\
\text { congophilia } \\
\text { (n=87) }\end{array}$ & $\begin{array}{l}\text { Negative urinary } \\
\text { congophilia } \\
(n=15)\end{array}$ & $F$ & $z$ & $\chi^{2}$ & $P$-value \\
\hline Age (years) & $30.7 \pm 5.3$ & $31.9 \pm 3.6$ & 0.635 & & / & 0.428 \\
\hline Gestational age at onset (weeks) & $28.1 \pm 4.2$ & $26.8 \pm 4.8$ & 1.167 & & / & 0.283 \\
\hline Gestational age at delivery (weeks) & $32.1 \pm 3.4$ & $36.2 \pm 3.1$ & 19.529 & & / & $<0.001$ \\
\hline Latency between onset and delivery (days) & $19(9,38)$ & $52(33,119)$ & / & -3.502 & / & $<0.001$ \\
\hline HELLP syndrome (\%) & 17/87 (19.5\%) & $1 / 15(6.7 \%)$ & / & / & 0.708 & 0.400 \\
\hline latrogenic prematurity (\%) & $80 / 87$ (92.0\%) & $6 / 15$ (40\%) & / & / & 26.111 & $<0.001$ \\
\hline
\end{tabular}

Values are mean \pm standard deviation, median (P25, P75), $n$ or $n / N(\%)$.

present findings also support those previously reported by Buhimschi, wherein women with PE were more likely to have urinary congophilia than their counterparts with gestational hypertension, chronic hypertension, or normotension (37). Recent studies have shown that ischemia, hypoxia, and production of pro-inflammatory cytokines, all of which are associated with PE, can lead to protein misfolding (40) and initiate ERS $(41,42)$, which results in the chronic activation of UPRs. Yung et al. have shown that activation levels of placental UPR in patients with early-onset PE are significantly higher than those in patients with late-onset PE or in normotensive controls, with similar values reported for the latter two groups (33). These findings provide molecular evidence that the production of placental misfolded proteins and placental ERS may contribute to early- but not to late-onset PE or normotensive controls. The present findings suggest that the rate of urinary congophilia in women with early-onset PE is significantly higher than that in the late-onset group and the normotensive group, indicating that the misfolded proteins in the urine may be linked to the pathogenesis of early-onset PE and the main source of misfolded proteins in 


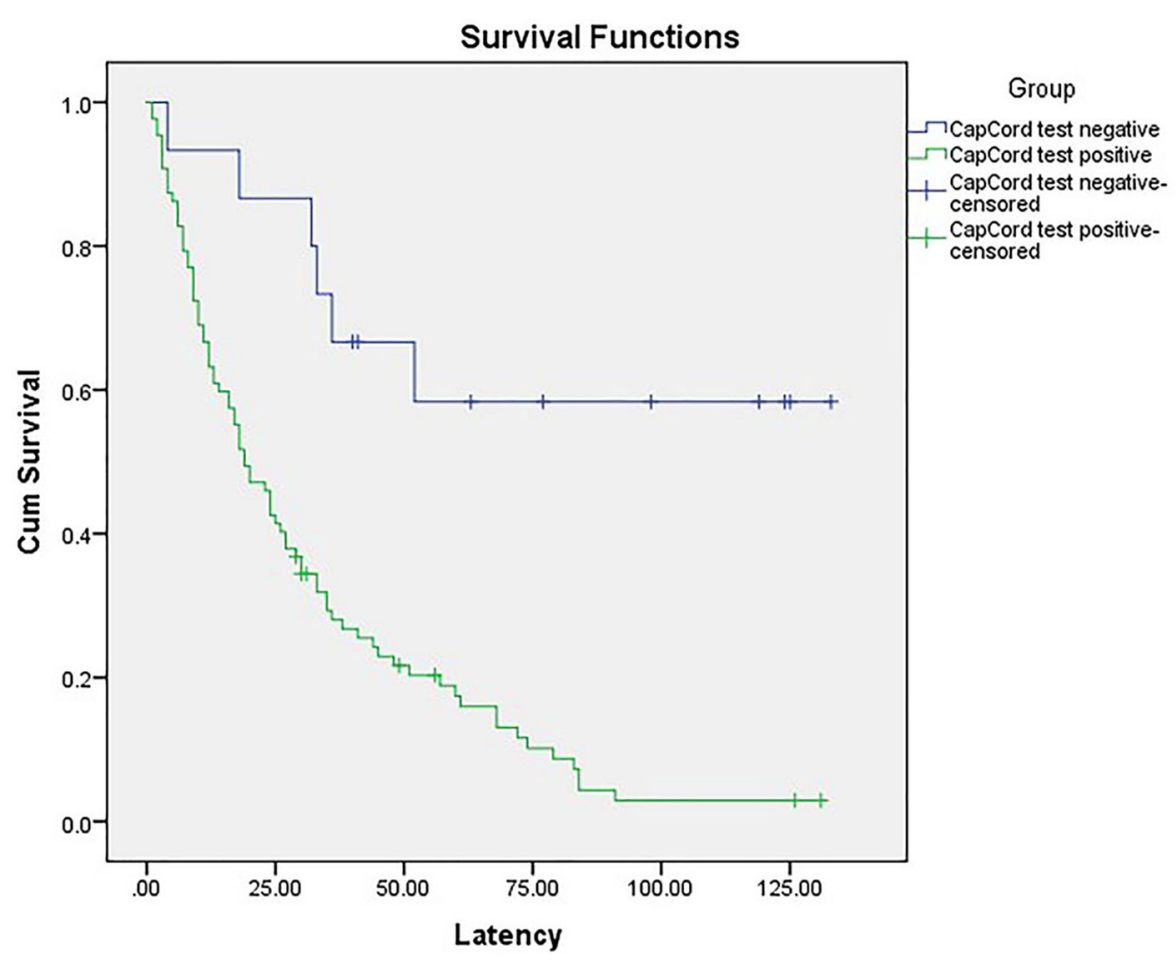

FIGURE 2 | The Kaplan-Meier survival curves showed higher rates of iatrogenic prematurity among patients with urinary congophilia than among their counterparts without this condition $\left(\chi^{2}=15.976, p<0.001\right)$.

the urine of patients with early-onset PE may be the placenta. In addition, our finding that the rate of urinary congophilia in the late-onset $\mathrm{PE}$ group is significantly higher than that in the normotensive group indicates that the main source of the misfolded proteins in the urine of patients with late-onset $\mathrm{PE}$ is different from that of the patients in the normotensive group, and probably not the placenta. Furthermore, previous studies have demonstrated the presence of the same types of misfolded proteins in both the plasma and urine of PE patients $(21,43)$. Accordingly, we propose that the urinary misfolded proteins in late-onset PE may be derived from the plasma.

Studies by Buhimschi et al. have demonstrated that the assessment of urinary congophilia with the Congo red dot test is useful for the prognostication of medically indicated delivery in patients with $\mathrm{PE}$, suggesting a close link between urinary congophilia and $\mathrm{PE}$ cases with severe maternal and fetal complications (33). In addition, previous studies have demonstrated that placental or early-onset $\mathrm{PE}$ is associated with a high risk of maternal and fetal complications (6, 44, 45). In the present study, the rate of urinary congophilia in the early-onset $\mathrm{PE}$ group was significantly higher than that in the late-onset group, suggesting an association between urinary congophilia and early-onset PE. Nevertheless, the present findings are inconsistent with those of Nagarajappa, whereby the Congo red retention value was lower in the early- than in the late-onset PE group. Furthermore, findings of this study suggest that urinary congophilia is an independent risk factor for iatrogenic prematurity in early-onset PE patients; in fact, the present findings indicate that early-onset PE patients with urinary congophilia are at a higher risk of adverse pregnancy outcomes than are their counterparts without urinary congophilia. Based on the present findings, we propose that urinary congophilia, confirmed with the CapCord test, may support the prognostication of pregnancy outcomes in patients with early-onset PE. In other words, the urine samples of patients with early-onset PE could be collected at the time of disease onset to detect the congophilia with CapCord test, the patients with positive urinary congophilia are more likely to present adverse maternal and neonatal outcomes such as HELLP syndrome and iatrogenic prematurity, so the medically indicated delivery, as an effective treatment, should be expected as early as possible for those patients. Conversely, the patients with negative urinary congophilia probably present a relatively better maternal and neonatal outcome, so the supportive and expectant treatment should be preferred, and iatrogenic prematurity would be avoided as far as possible to extend the latency period between the onset and delivery.

In summary, results of this study suggest that the main sources of the urinary misfolded proteins in early- and late-onset PE seem different, the former may be the placenta, but the latter may be the plasma. To the best of our knowledge, this study is first to assess the association of urinary congophilia confirmed with the CapCord test with the pregnancy outcomes of Chinese patients with early-onset PE. Urinary congophilia confirmed with the CapCord test may be useful in the prognostication of pregnancy outcomes in patients with early-onset PE. However, this study 
has some limitations. First, the study population was composed of Chinese patients; thus, the conclusion of this study may not be applicable to other populations. Second, the sample size is relatively small, and the error of the CapCord test and influence of gestational age on urinary congophilia are not excluded in this study. Thus, more studies that consider the influence of gestational age on urinary congophilia with CapCord test are needed to validate the present findings.

\section{DATA AVAILABILITY STATEMENT}

The raw data supporting the conclusions of this article will be made available by the authors, without undue reservation.

\section{ETHICS STATEMENT}

The studies involving human participants were reviewed and approved by Institutional Review Board of Shengjing

\section{REFERENCES}

1. Duley L. The global impact of pre-eclampsia and eclampsia. Semin Perinatol. (2009) 33:130-7. doi: 10.1053/j.semperi.2009.02.010

2. Brown MA, Magee LA, Kenny LC, Karumanchi SA, McCarthy FP, Saito S, et al. Hypertensive disorders of pregnancy: ISSHP classification, diagnosis, and management recommendations for international practice. Hypertension. (2018) 72:24-43. doi: 10.1161/HYPERTENSIONAHA.117.10803

3. Wildman K, Bouvier-Colle MH, Group M. Maternal mortality as an indicator of obstetric care in Europe. BJOG. (2004) 111:164-9. doi: 10.1046/j.1471-0528.2003.00034.x-i1

4. Sircar M, Thadhani R, Karumanchi SA. Pathogenesis of preeclampsia. Curr Opin Nephrol Hypertens. (2015) 24:131-8. doi: 10.1097/MNH.0000000000000105

5. Ghulmiyyah L, Sibai B. Maternal mortality from preeclampsia/eclampsia. Semin Perinatol. (2012) 36:56-9. doi: 10.1053/j.semperi.2011.09.011

6. von Dadelszen P, Magee LA, Roberts JM. Subclassification of preeclampsia. Hypertens Pregnancy. (2003) 22:143-8. doi: 10.1081/PRG-120021060

7. Odegard RA, Vatten LJ, Nilsen ST, Salvesen KA, Austgulen R. Risk factors and clinical manifestations of pre-eclampsia. BJOG. (2000) 107:1410-6. doi: 10.1111/j.1471-0528.2000.tb11657.x

8. Levine RJ, Maynard SE, Qian C, Lim KH, England LJ, Yu KF, et al. Circulating angiogenic factors and the risk of preeclampsia. N Engl J Med. (2004) 350:67283. doi: 10.1056/NEJMoa031884

9. Masuyama H, Segawa T, Sumida Y, Masumoto A, Inoue S, Akahori Y, et al. Different profiles of circulating angiogenic factors and adipocytokines between early- and late-onset pre-eclampsia. BJOG. (2010) 117:314-20. doi: 10.1111/j.1471-0528.2009.02453.x

10. Gilbert JS, Babcock SA, Granger JP. Hypertension produced by reduced uterine perfusion in pregnant rats is associated with increased soluble fms-like tyrosine kinase-1 expression. Hypertension. (2007) 50:1142-7. doi: 10.1161/HYPERTENSIONAHA.107.096594

11. Makris A, Thornton C, Thompson J, Thomson S, Martin R, Ogle R, et al. Uteroplacental ischemia results in proteinuric hypertension and elevated sFLT-1. Kidney Int. (2007) 71:977-84. doi: 10.1038/sj.ki.5002175

12. Kaufmann P, Black S, Huppertz B. Endovascular trophoblast invasion: implications for the pathogenesis of intrauterine growth retardation and preeclampsia. Biol Reprod. (2003) 69:1-7. doi: 10.1095/biolreprod.102. 014977

13. Aguzzi A, Haass C. Games played by rogue proteins in prion disorders and Alzheimer's disease. Science. (2003) 302:814-8. doi: 10.1126/science.1087348

14. Soto C. Unfolding the role of protein misfolding in neurodegenerative diseases. Nat Rev Neurosci. (2003) 4:49-60. doi: 10.1038/nrn1007
Hospital of China Medical University. Written informed consent for participation was not required for this study in accordance with the national legislation and the institutional requirements.

\section{AUTHOR CONTRIBUTIONS}

BC: conceptualized the study and wrote the protocol and the manuscript. XY, XL, and JX: participated in the experiment and confirmed the experimental results. JD: interpreted the data and reviewed and edited the manuscript. All authors contributed to the article and approved the submitted version.

\section{FUNDING}

This study was supported by Scientific Research Fund of Liaoning Provincial Education Department (CN). Award Number: FWZR2020009.
15. Labbadia J, Morimoto RI. The biology of proteostasis in aging and disease. Аnnu Rev Biochem. (2015) 84:435-64. doi: 10.1146/annurev-biochem-060614-033955

16. Belay ED. Transmissible spongiform encephalopathies in humans. Annu Rev Microbiol. (1999) 53:283-314. doi: 10.1146/annurev.micro.53.1.283

17. Iwasaki Y. Creutzfeldt-Jakob disease. Neuropathology. (2017) 37:174-88. doi: 10.1111/neup. 12355

18. Brown K, Mastrianni JA. The prion diseases. J Geriatr Psychiatry Neurol. (2010) 23:277-98. doi: 10.1177/0891988710383576

19. Buhimschi IA, Zhao G, Funai EF, Harris N, Sasson IE, Bernstein IM, et al. Proteomic profiling of urine identifies specific fragments of SERPINA1 and albumin as biomarkers of preeclampsia. Am J Obstet Gynecol. (2008) 199:551 e1-16. doi: 10.1016/j.ajog.2008.07.006

20. Millen KR, Buhimschi CS, Zhao G, Rood KM, Tabbah S, Buhimschi IA. Serum and urine thioflavin-T-enhanced fluorescence in severe preeclampsia. Hypertension. (2018) 71:1185-92. doi: 10.1161/HYPERTENSIONAHA.118.11034

21. Buhimschi IA, Nayeri UA, Zhao G, Shook LL, Pensalfini A, Funai EF, et al. Protein misfolding, congophilia, oligomerization, and defective amyloid processing in preeclampsia. Sci Transl Med. (2014) 6:245ra92. doi: 10.1126/scitranslmed.3008808

22. Tong M, Cheng SB, Chen Q, DeSousa J, Stone PR, James JL, et al. Aggregated transthyretin is specifically packaged into placental nano-vesicles in preeclampsia. Sci Rep. (2017) 7:6694. doi: 10.1038/s41598-017-07017-x

23. Cater JH, Kumita JR, Zeineddine Abdallah R, Zhao G, Bernardo-Gancedo A, Henry A, et al. Human pregnancy zone protein stabilizes misfolded proteins including preeclampsia- and Alzheimer's-associated amyloid beta peptide. Proc Natl Acad Sci USA. (2019) 116:6101-10. doi: 10.1073/pnas.1817298116

24. Cheng SB, Nakashima A, Sharma S. Understanding pre-eclampsia using Alzheimer's etiology: an intriguing viewpoint. Am J Reprod Immunol. (2016) 75:372-81. doi: 10.1111/aji.12446

25. Li XM, Liu XM, Xu J, Du J, Cuckle H. Late pregnancy screening for preeclampsia with a urinary point-of-care test for misfolded proteins. PLoS ONE. (2020) 15:e0233214. doi: 10.1371/journal.pone.0233214

26. Ashburn TT, Han H, McGuinness BF, Lansbury Jr PT. Amyloid probes based on congo red distinguish between fibrils comprising different peptides. Chem Biol. (1996) 3:351-8. doi: 10.1016/S1074-5521(96)90118-0

27. Stopa B, Piekarska B, Konieczny L, Rybarska J, Spolnik P, Zemanek G, et al. The structure and protein binding of amyloid-specific dye reagents. Acta Biochim Pol. (2003) 50:1213-27. doi: 10.18388/abp.2003_3645

28. Klunk WE, Pettegrew JW, Abraham DJ. Quantitative evaluation of congo red binding to amyloid-like proteins with a beta-pleated sheet conformation. $J$ Histochem Cytochem. (1989) 37:1273-81. doi: 10.1177/37.8.2666510 
29. Inouye H, Kirschner DA. Alzheimer's beta-amyloid: insights into fibril formation and structure from congo red binding. Subcell Biochem. (2005) 38:203-24. doi: 10.1007/0-387-23226-5_10

30. Buell AK, Dobson CM, Knowles TP, Welland ME. Interactions between amyloidophilic dyes and their relevance to studies of amyloid inhibitors. Biophys J. (2010) 99:3492-7. doi: 10.1016/j.bpj.2010. 08.074

31. Burton GJ, Yung HW, Cindrova-Davies T, Charnock-Jones DS. Placental endoplasmic reticulum stress and oxidative stress in the pathophysiology of unexplained intrauterine growth restriction and early onset preeclampsia. Placenta. (2009) 30(Suppl. A):S43-8. doi: 10.1016/j.placenta.2008. 11.003

32. Mizuuchi M, Cindrova-Davies T, Olovsson M, Charnock-Jones DS, Burton GJ, Yung HW. Placental endoplasmic reticulum stress negatively regulates transcription of placental growth factor via ATF4 and ATF6beta: implications for the pathophysiology of human pregnancy complications. J Pathol. (2016) 238:550-61. doi: 10.1002/path.4678

33. Yung HW, Atkinson D, Campion-Smith T, Olovsson M, Charnock-Jones DS, Burton GJ. Differential activation of placental unfolded protein response pathways implies heterogeneity in causation of early- and late-onset preeclampsia. J Pathol. (2014) 234:262-76. doi: 10.1002/path.4394

34. Hetz C. The unfolded protein response: controlling cell fate decisions under ER stress and beyond. Nat Rev Mol Cell Biol. (2012) 13:89-102. doi: $10.1038 / \mathrm{nrm} 3270$

35. Kaufman RJ, Scheuner D, Schroder M, Shen X, Lee K, Liu CY, et al. The unfolded protein response in nutrient sensing and differentiation. Nat Rev Mol Cell Biol. (2002) 3:411-21. doi: 10.1038/nrm829

36. Zhang K, Kaufman RJ. From endoplasmic-reticulum stress to the inflammatory response. Nature. (2008) 454:455-62. doi: 10.1038/nature07203

37. McCarthy FP, Adetoba A, Gill C, Bramham K, Bertolaccini M, Burton GJ, et al. Urinary congophilia in women with hypertensive disorders of pregnancy and preexisting proteinuria or hypertension. Am J Obstet Gynecol. (2016) 215:464 e1-7. doi: 10.1016/j.ajog.2016.04.041

38. Nagarajappa C, Rangappa SS, Suryanarayana R, Balakrishna S. Urinary congophilia in preeclampsia: experience from a rural tertiary-care hospital in India. Pregnancy Hypertens. (2018) 13:83-6. doi: 10.1016/j.preghy.2018.05.006

39. Rood KM, Buhimschi CS, Dible T, Webster S, Zhao G, Samuels P, et al. Congo red dot paper test for antenatal triage and rapid identification of preeclampsia. EClin Med. (2019) 8:47-56. doi: 10.1016/j.eclinm.201 9.02.004
40. Mao XR, Crowder CM. Protein misfolding induces hypoxic preconditioning via a subset of the unfolded protein response machinery. Mol Cell Biol. (2010) 30:5033-42. doi: 10.1128/MCB.00922-10

41. Paschen W, Mengesdorf T. Endoplasmic reticulum stress response and neurodegeneration. Cell Calcium. (2005) 38:409-15. doi: 10.1016/j.ceca.2005.06.019

42. Jian B, Hsieh CH, Chen J, Choudhry M, Bland K, Chaudry I, et al. Activation of endoplasmic reticulum stress response following trauma-hemorrhage. Biochim Biophys Acta. (2008) 1782:621-6. doi: 10.1016/j.bbadis.2008.08.007

43. Buhimschi I, Zhao G, Saade G, Buhimschi CS. Evidence for alpha-1antitrypsin (A1AT) polymerization in preeclampsia: a novel mechanism for endothelial cell injury. Am J Obstetr Gynecol. (2006) 195:S150. doi: 10.1016/j.ajog.2006.10.526

44. Mongraw-Chaffin ML, Cirillo PM, Cohn BA. Preeclampsia and cardiovascular disease death: prospective evidence from the child health and development studies cohort. Hypertension. (2010) 56:166-71. doi: 10.1161/HYPERTENSIONAHA.110.150078

45. Paruk F, Moodley J. Maternal and neonatal outcome in earlyand late-onset pre-eclampsia. Semin Neonatol. (2000) 5:197-207. doi: $10.1053 /$ siny.2000.0023

Conflict of Interest: XY, XL, and JX are employed by Shuwen Biotech Company Ltd., China.

The remaining authors declare that the research was conducted in the absence of any commercial or financial relationships that could be construed as a potential conflict of interest.

Publisher's Note: All claims expressed in this article are solely those of the authors and do not necessarily represent those of their affiliated organizations, or those of the publisher, the editors and the reviewers. Any product that may be evaluated in this article, or claim that may be made by its manufacturer, is not guaranteed or endorsed by the publisher.

Copyright (C) $2021 \mathrm{Cai}, \mathrm{Yuan}, \mathrm{Li}, \mathrm{Xu}$ and Du. This is an open-access article distributed under the terms of the Creative Commons Attribution License (CC BY). The use, distribution or reproduction in other forums is permitted, provided the original author(s) and the copyright owner(s) are credited and that the original publication in this journal is cited, in accordance with accepted academic practice. No use, distribution or reproduction is permitted which does not comply with these terms. 